\title{
High Intensity Dependence of Auditory Evoked Dipole Source Activity Indicates Decreased Serotonergic Activity in Abstinent Ecstasy (MDMA) Users
}

Frank Tuchtenhagen, M.D., Jörg Daumann, Christina Norra, M.D., René Gobbelé, M.D., Steffanie Becker, Susanne Pelz, Henning Sass, M.D., Helmut Buchner, M.D., and Euphrosyne Gouzoulis-Mayfrank, M.D.

Neurotoxic damage of central serotonergic systems has been demonstrated in numerous animal studies after exposure to methylenedioxyamphetamines (ecstasy). A high intensity dependence of auditory evoked potentials and, particularly, of the tangential N1/P2 source activity has been associated with low levels of serotonergic neurotransmission in humans. We performed an auditory evoked potentials study in 28 abstinent recreational ecstasy users and two equally sized groups of cannabis users and nonusers. The ecstasy users exhibited an increase of the amplitude of the tangential N1/P2 source activity with higher stimulus intensities; whereas, both control groups failed to exhibit this feature. These data are in line with the hypothesis that abstinent ecstasy users present with diminished central serotonergic activity. This feature of information processing is probably related to the well-recognized neurotoxic potential of ecstasy. Our data indicate that recreational ecstasy use may cause long-term alterations in the function (and possibly structure) of the human brain. [Neuropsychopharmacology 22:608-617] (C) 2000 American College of Neuropsychopharmacology. Published by Elsevier Science Inc.
KEY WORDS: Ecstasy, 3,4-

methylenedioxymethamphetamine; MDMA; Neurotoxicity; Serotonin; Auditory evoked potentials

Ecstasy (3,4-methylenedioxymethamphetamine = MDMA and related congerers: MDA, MDEA) is a group of popular recreational drugs with neurotoxic effects upon central serotonergic systems. Widespread neurotoxic

From the Department of Psychiatry and Psychotherapy (FT, JD, CN, SB, SP, EGM, HS), and Department of Neurology (RG, HB), Medical Faculty of the University of Technology, Pauwelsstrasse 30, D-52074 Aachen, Germany

Address correspondence to: E. Gouzoulis-Mayfrank, M.D., Department of Psychiatry and Psychotherapy, Medical Faculty of the University of Technology (RWTH), Pauwelsstrasse 30, D-52074 Aachen, Germany.

Received May 25, 1999; revised October 20, 1999; accepted October 27, 1999. damage has been demonstrated in numerous animal studies with several species, including nonhuman primates (Battaglia et al. 1987, 1988; Molliver et al. 1990; O'Hearn et al. 1988; Ricaurte et al. 1985, 1988, 1992; Schmidt et al. 1987, Wilson et al. 1989). Notably, monkeys seem to be more susceptible to the neurotoxic effects of ecstasy than lower mammals. Although recovery from neurotoxic damage was almost complete in most rats after 12 months, in nonhuman primates, neurotoxic brain alterations were still detectable as long as 18 months after MDMA-exposure (Battaglia et al. 1988; Fischer et al. 1995; Ricaurte et al. 1988, 1992). The lowest MDMA dose, which elicited long-term structural damage in serotonergic neurons of nonhuman primates, was $5 \mathrm{mg} / \mathrm{kg}$ SC twice daily for 4 days (Ricaurte et al. 1992). Although some heavy users take ecstasy in quantities that approach those experimental doses, the ma- 
jority of recreational users do not. However, the threshold dose for human neurotoxicity is not clear, and humans may be more susceptible than primates. In addition, it is possible that the cumulative doses ingested by typical recreational users over a longer period of regular use bear a similar neurotoxic risk as high experimental doses administered within a short period of time.

In a recent positron emission tomography (PET) study with the selective 5-HT transporter ligand McN5652, abstinent ecstasy users showed decreased brain 5-HT transporter binding as compared with controls, and this decrease correlated with the extent of previous ecstasy use (McCann et al. 1998). Hence, this finding probably reflects neurotoxic brain damage. Serotonergic systems are involved in numerous functions including regulation of mood and drive, cognition, vegetative function, pain, and neuroendocrine secretion. So far, mild memory impairments (Bolla et al. 1998; Krystal et al. 1992; Morgan 1999), elevated impulsivity (Morgan 1998) and neuroendocrine abnormalities (Gerra et al. 1998; Price et al. 1989) have been demonstrated in abstinent ecstasy users. In addition, depressive and anxiety disorders after ecstasy use might also reflect, at least in part, a neurotoxic serotonergic damage (Benazzi and Mazzoli 1991; Gouzoulis-Mayfrank et al. 1996; Green et al. 1995; McCann and Ricaurte 1991; McGuire et al. 1994; Pallanti and Mazzi 1992).

The aim of our investigation was to study an aspect of information processing in abstinent ecstasy users, which is thought to reflect the level of central serotonergic neurotransmission (Hegerl and Juckel 1993). For this purpose, we recorded auditory evoked potentials (AEP) and used the method of dipole source analysis. An old debate exists on the dependence of the amplitude of sensory evoked potentials on stimulus intensity (Buchsbaum and Silverman 1968; review in: Carillo-dela-Pena 1992; Von Knorring and Perris 1981; Von Knorring 1982; Zuckerman et al. 1974, 1988). In more recent years, extensive work suggested that a high intensity dependence is associated with a low functioning of serotonergic neurotransmission (Hegerl and Juckel 1993; Hegerl et al. 1994, 1996; Von Knorring 1982; Von Knorring and Perris 1981). Several lines of evidence support the existence of this link. The intensity dependence of visually evoked potentials (VEP) correlated negatively with the cerebrospinal fluid concentration of the serotonin metabolite 5-Hydroxyindoleacetic acid (5-HIAA) (Von Knorring and Perris 1981). Similarly, serotonin serum levels in depressive patients correlated negatively with the intensity dependence of the auditory evoked N1/P2 component (Hegerl et al. 1991). In addition, the intensity dependence of VEPs was decreased by serotonergic substances such as zimelidine (Von Knorring et al. 1980; Von Knorring 1982). The auditory evoked N1/P2 component and, particularly, its tangential dipole source activity increased strongly with higher stimulus intensities in persons with personality traits thought to be associated with diminished serotonergic activity such as high novelty or sensation seeking (Zuckerman 1990; Juckel et al. 1994; Hegerl et al. 1995a,b). Finally, a high intensity dependence of the auditory evoked N1/P2 component predicted good clinical response to such serotonergic drugs as fenfluramine and lithium in clinical populations (Bruneau et al. 1989; Hegerl et al. 1987, 1992).

According to studies of dipole source analysis (Scherg 1991; Scherg et al. 1989), the tangentially oriented dipole of the N1/P2 component of AEP represents mainly the activity of the primary auditory cortex; whereas, the radially oriented dipole represents the activity of the secondary auditory cortex in the more lateral part of the temporal lobe (Hegerl et al. 1994). Although serotonergic fibers from the raphe nuclei project to virtually every brain area, the highest rate of serotonergic innervation has been found in the primary sensory cortex; whereas, serotonergic innervation in the secondary sensory areas is clearly lower (Azmitia and Gannon 1986; Campbell et al. 1987; Lewis et al. 1987; Morrison and Foote 1986; Takeuchi and Sano 1983). Hence, the intensity dependence of the tangential auditory evoked N1/P2 source activity may be a more sensitive electrophysiological measure of the serotonergic innervation of the cerebral cortex than the amplitude of the entire N1/P2 component (Hegerl and Juckel 1993).

Based on this evidence, we hypothesized that a high dependence of the tangential N1/P2 source activity on stimulus intensity should indicate a low serotonergic innervation in abstinent ecstasy users. This, in turn, might be an index of long-term neurotoxic brain damage attributable to the use of ecstasy.

\section{METHODS}

\section{Subjects}

We enrolled 28 ecstasy users who reported regular use of ecstasy over 6 months or longer with a minimum frequency of twice per month within the last 2 years or use of ecstasy on at least 25 occasions during the last 2 years (inclusion criteria). Recruitment was through personal contacts in the dance scene by students who were involved in the study and through the snow ball technique. Exclusion criteria were: (1) regular use of other legal or illegal psychotropic drugs, with the exception of cannabis (regular use was defined as use once per month or more frequently over 6 months or longer within the last 2 years); and (2) regular heavy use of alcohol (defined as severe drunkenness occurring at a frequency of at least twice per month). Because almost every ecstasy user smokes hashish, it was impossible to recruit an "exclusive" ecstasy user group. Therefore, we enrolled two control groups. The first one consisted of 
28 healthy persons with no previous or current history of drug or alcohol abuse who were matched for age, sex, and education with the ecstasy user group. The second control group consisted of 28 persons who were matched for age, sex, education, and cannabis use with the ecstasy user group, but did not use any other psychotropic substances except for cannabis. Exclusion criteria for all participants were any current or previous Axis I psychiatric diagnoses (except for drug abuse in the two user groups), any organic brain disorder, and any relevant general medical disease requiring regular medication. Subjects were screened for inclusion and exclusion criteria by means of a preliminary telephone interview, which was followed by a personal interview and medical history, including the Scheduled Interview for the Diagnostic and Statistical Manual of Mental Disorders IV (DSM-IV) and a detailed history of drug abuse. In addition, subjects completed the two self-questionnaires Sensation Seeking Scale SSS V (Zuckerman et al. 1978) and Barratt Impulsiveness Scale (Barratt 1985). The ecstasy users agreed to abstain from ecstasy use for at least 7 days before the study. Ecstasy and cannabis users agreed to abstain from use of cannabis at the study day. Drug screens were performed on the study day with urine samples for the following substance groups: amphetamines, methamphetamines, cocaine and its metabolite, marijuana, benzodiazepines, barbiturates, and opiates. A positive screen for any substance except for cannabis was an exclusion criterion. All subjects were paid for participating in the study and gave written informed consent after the study was described to them in detail. The study was approved by the local ethics committee at the RWTH Aachen.

\section{Procedures}

Auditory evoked potentials with a passive listening paradigm were recorded using a Nicolet Pathfinder $\mathrm{Mega}^{\mathrm{R}}$ and a 32-channel Nicolet SC-2000 ${ }^{\mathrm{R}}$ preamplifier. Recordings were performed in a sound-attenuated and darkened room. Subjects were seated in a comfortable chair and were instructed to relax, but keep their eyes open, and to listen passively to the acoustic stimuli without paying special attention to them. Thirty-three $\mathrm{Ag}^{+} / \mathrm{Cl}^{-}$scalp electrodes were applied using a modified 10/20 scheme with $\mathrm{Fz}$ as reference. Transition resistance was less than $5 \mathrm{k} \Omega$. Stimuli consisted of sinus tones of $1 \mathrm{kHz}$ frequency and $30 \mathrm{~ms}$ duration with a rise and fall time of $10 \mathrm{~ms}$. Tones were presented binaurally with a closed headphone (Phillips ${ }^{\mathrm{R}}$ SBC 484). Interstimulus intervals were randomized between 1.5 and $2.5 \mathrm{~s}$. Stimuli were presented in four blocks of 100 sweeps each for every one of four intensities $(60,70,80$, and $90 \mathrm{~dB})$ in increasing succession. Recordings were performed over a 600-ms time interval per sweep with a 200 -ms prestimulus interval and were averaged for each channel. Artifact rejection was performed in the range of $\pm 100 \mu \mathrm{V}$ : peaks with amplitudes larger than $100 \mu \mathrm{V}$ were rejected for averaging to reduce eye movement artifacts.

Data were converted into BESA 2.1 software (MEGIS, Munich Germany) for dipole source analysis for each subject. After filtering with a low pass of $30 \mathrm{~Hz}$, $24 \mathrm{~dB} /$ oct slope and a high pass of $0.5 \mathrm{~Hz}, 12 \mathrm{~dB} /$ oct slope, the four blocks of each intensity were averaged separately for each subject. Four frontally located channels were excluded from further analysis because of eye movement artifacts. For source deconvolution, a three shell spherical head model assuming a scalp thickness

\section{A}

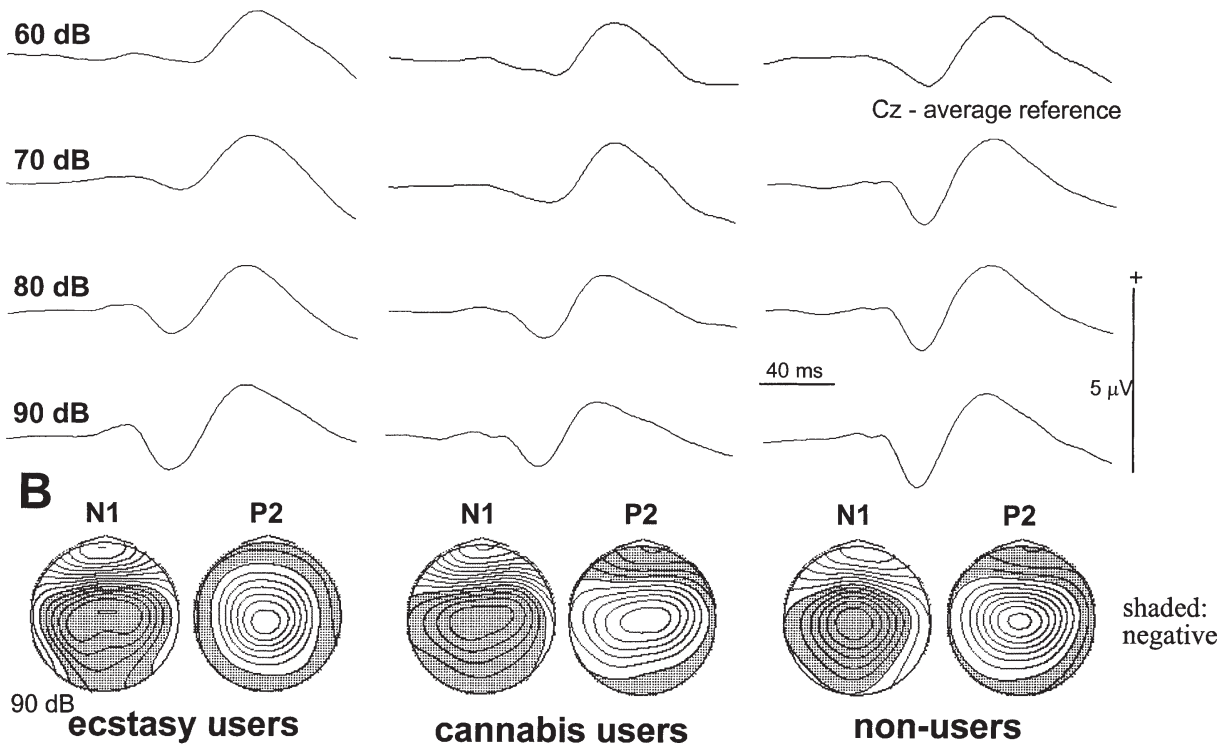

Figure 1. (A) Auditory evoked potentials, grand-average data (Cz-average reference) of the ecstasy users, the cannabis users, and the control subjects to four different stimulus intensities (60, $70,80$, and $90 \mathrm{~dB})$. Ecstasy users showed an increase of the N1/ P2 amplitude with stimulus intensity; whereas, there was no increase in the cannabis and control groups. (B) Maps at the N1 and P2 latency $(90 \mathrm{~dB})$ in the three groups, showing very similar topography of the electric fields. 
of $6 \mathrm{~mm}(0.33[1 /(\Omega \mathrm{m})])$, a skull thickness of $7 \mathrm{~mm}$ $(0.0042[1 /(\Omega \mathrm{m})])$, and a conductivity of the brain of $0.33[1 /(\Omega \mathrm{m})]$ was applied. On the basis of the grandaverage data of the control subjects, a source model was constructed consisting of two pairs of tangential and radial dipoles placed symmetrically in the region of the auditory cortex. Figure 1 presents the data of the three groups at one selected channel to each stimulus intensity (1A) together with the maps at the N1 and P2 peaks (1B). Maps were very similar between the three groups. Figure 2 presents the source model $(2 \mathrm{~A})$ and the source activity in time for the grand average of all subjects (2B). This source model was applied to the data of each subject and each stimulus intensity. The model explained the data with a goodness of fit $(\mathrm{GoF})$ between $83.0 \%$ (SD 9.0) in the $60 \mathrm{~dB}$ stimulus intensity and $67.0 \%$ (SD 11.7) in the $90 \mathrm{~dB}$ intensity data. There was a significant decrease of the GoF stepwise depending on the stimulus intensity $(p<.01)$, pointing to increasing noise at higher stimulus intensities. Noteworthy, there was no significant or even marginal difference of the GoF between the groups; thus, the data were explained to a very similar extent in the control and the ecstasy group by the model. Thus, in accordance with the maps (Fig. 1B), one single model was adequate to model the data in all three groups. The latencies and amplitudes of the major deflections of the source activities were determined and used for further statistics.

\section{Statistics}

The latencies and amplitudes of the two dipoles of the $\mathrm{N} 1 / \mathrm{P} 2$ components were analyzed by means of analysis of variance (ANOVA) using the stimulus intensity (60, $70,80,90 \mathrm{~dB}$ ) as the within-subject factor and the group (ecstasy users, cannabis users, nonusers) as the betweensubject factor. ANOVA was followed by post hoc tests (Scheffé). In addition, the amplitudes of the tangential dipoles were analyzed for each group separately using paired two-tailed $t$-tests and subsequent Holm's procedure $(60 / 70,70 / 80,80 / 90 \mathrm{~dB})$. The relation between the intensity dependence of the tangential dipole of the N1/ P2 component and the previous drug use was analyzed with Pearson's correlation coefficient in the ecstasy user group. For this analysis, the arithmetic differences of the amplitudes (70-60 dB, 80-70 dB, 90-80 dB, 90-60 dB) were correlated with the frequency, intensity, and duration of use of ecstasy and cannabis as assessed in our interview (see Table 1). Group differences in the psychometric scores of the Sensation Seeking Scale SSS V and the Barratt Impulsiveness Scale were analyzed by means of ANOVA and post hoc tests (Scheffé). Finally, because of literature reports of a strong intensity dependence of sensory evoked potentials being associated with high novelty seeking and related personality characteristics (Zuckerman 1990; Juckel et al. 1995; Hegerl et al. 1995a, 1995b), we correlated the psychometric scores of the above mentioned instruments with the arithmetic differences of the amplitudes of the tangential dipoles. All procedures were performed using SPSS version 7.5.

\section{RESULTS}

The three groups were similar in terms of sex distribution, age, and educational level (Table 2 ). Although the
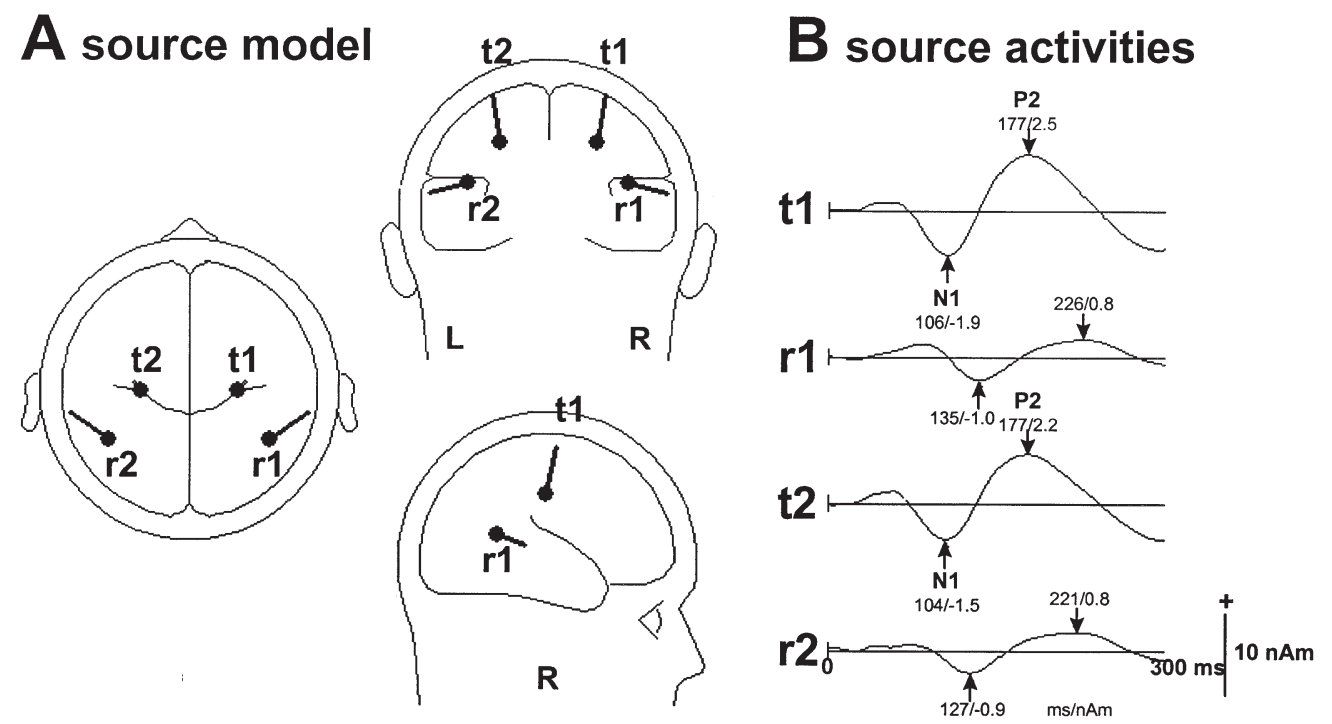

Figure 2. (A) Source model, consisting of two pairs of tangential (t) and radial dipoles (r) placed symmetrically in the region of the auditory cortex. (B) Source activities with marked N1/P2 components as derived by source deconvolution of the data. 
Table 1. Patterns of Ecstasy and Cannabis Use in the Two User Groups $(n=28$ in Each Group)

\begin{tabular}{|c|c|c|c|}
\hline \multirow[b]{2}{*}{ Patterns of Use } & \multicolumn{2}{|c|}{ Ecstasy Users } & \multirow{2}{*}{$\begin{array}{c}\text { Cannabis Users } \\
\text { Cannabis Use }\end{array}$} \\
\hline & Ecstasy Use & Cannabis Use & \\
\hline Regular/sporadic/no use & $26 / 2 / 0$ & $22 / 1 / 5$ & $23 / 2 / 3$ \\
\hline Estimated total dose & $\begin{array}{l}93.4 \pm 119.9 \text { tablets } \\
\quad \text { (range: } 20-500)\end{array}$ & & \\
\hline $\begin{array}{l}\text { Average frequency of use } \\
\text { (days per month) }\end{array}$ & $\begin{array}{l}2.4 \pm 1.6 \\
\quad \text { (range: } 0,75-8)\end{array}$ & $20.7 \pm 11.5$ & $20.95 \pm 10.2$ \\
\hline $\begin{array}{l}\text { Average estimated daily or } \\
\text { one-night dose }\end{array}$ & $\begin{array}{l}1.4 \pm 0.9 \text { tablets } \\
\quad \text { (range: } 0.5-3.5 \text { ) }\end{array}$ & $650 \pm 635 \mathrm{mg}$ daily & $724 \pm 608$ mg daily \\
\hline $\begin{array}{l}\text { Duration of regular use in } \\
\text { regular users }\end{array}$ & $\begin{array}{l}27 \pm 18 \text { months } \\
\text { (range: } 6-60 \text { ) }\end{array}$ & $66.6 \pm 37$ months & $35.1 \pm 24$ months \\
\hline Age at onset of use & $\begin{array}{r}19.4 \pm 3.3 \text { years } \\
\quad \text { (range; } 14-27)\end{array}$ & $16.6 \pm 2.9$ years & $17.1 \pm 2.4$ years \\
\hline Time since last dose & $\begin{array}{l}41 \pm 71.1 \text { days } \\
\text { (range: } 7 \text { days }-1 \text { year, } \\
\text { median: } 23 \text { days) }\end{array}$ & $\begin{array}{l}4.3 \pm 5.3 \text { days } \\
\quad \text { (median: } 2 \text { days) }\end{array}$ & $\begin{array}{l}4.0 \pm 15.5 \text { days } \\
\quad \text { (median: } 1 \text { day) }\end{array}$ \\
\hline $\begin{array}{l}\text { THC-screen in urine } \\
\text { sample on study day }\end{array}$ & 2010 & 17 positive/11 negative & 20 positive/ 8 negative \\
\hline
\end{tabular}

level of education was slightly lower in the ecstasy group, the differences were not statistically significant ( $\chi^{2}$-test $p .59$, educational levels $1-3$ and $4-5$ were pooled together for testing). The data for ecstasy and cannabis use are given in Table 1 . The two user groups were similar for the extent of previous use of cannabis. Ecstasy users had used ecstasy over 27 months on average. The average estimated total dose was 93.4 ecstasy tablets. Hence, the average extent of use was about 3.5 ecstasy tablets per month, which is a typical recreational and not a very heavy use. Most ecstasy users had taken the drug for the last time 2 to 8 weeks before the study. In four cases, this time period was shorter (7-10 days); whereas, in two cases, it was considerably longer (6-12 months).

The latency of the N1/P2 component showed a nonsignificant tendency to be shortened by an increasing stimulus intensity, but there was no significant or marginal difference between the three groups. Similarly, the radial sources of the N1/P2 component showed no significant effect of stimulus intensity and no significant difference between control groups and ecstasy users. Therefore, these data are not shown.
Descriptive data (mean values \pm standard deviation) of the amplitude of the tangential dipoles of the N1/P2 component of the AEPs are presented in Figure 3. Because there were no notable hemispheric differences, the amplitudes of the left and the right tangential dipole were averaged for reducing the number of data. Because of artifacts and technical reasons, there were missing data for single stimulus intensities in some subjects. Hence, the ANOVA was run with the data of 23 ecstasy users, 25 cannabis users, and 27 nonusers. ANOVA revealed a significant main effect of stimulus intensity ( $p=.002, \mathrm{~F}=5.158, \mathrm{df}=3)$, a marginal effect of group ( $p=0.084, \mathrm{~F}=2.561, \mathrm{df}=2)$ and a significant interaction stimulus intensity $\times$ group $(p=$ $.000, \mathrm{~F}=8.151, \mathrm{df}=6$ ). Post hoc tests demonstrated no significant group differences at the lower intensities of 60 and $70 \mathrm{~dB}$. At $80 \mathrm{~dB}$, the ecstasy user group differed significantly from the cannabis user group $(p=.017)$, but not from the nonuser group $(p=.133)$. At $90 \mathrm{~dB}$, the ecstasy user group differed from both control groups (ecstasy users/nonusers: $p=.007$; ecstasy users/cannabis users: $p=$ .000). There were no significant differences between the two control groups at any stimulus intensity.

Table 2. Demographic Data of Ecstasy Users and Control Groups ( $n=28$ in Each Group)

\begin{tabular}{|c|c|c|c|}
\hline & Ecstasy Users & Cannabis Users & Nonusers \\
\hline Mean age in years (range) & $23.25(18-29)$ & $22.9(18-31)$ & $23.5(18-30)$ \\
\hline Men : women & $16: 12$ & $15: 13$ & $17: 11$ \\
\hline \multicolumn{4}{|l|}{ Level of education } \\
\hline 1. No school-leaving exam/ at least 9 years of education & 1 & 0 & 0 \\
\hline $\begin{array}{l}\text { 2. Basic school-leaving exam after form } 9 \\
\text { (Hauptschulabschluß) }\end{array}$ & 2 & 2 & 0 \\
\hline $\begin{array}{l}\text { 3. Intermediate school-leaving exam after form } 10 \\
\text { (Realschule/mittlere Reife) }\end{array}$ & 8 & 5 & 8 \\
\hline $\begin{array}{l}\text { 4. Highest school-leaving exam qualifying for admission to } \\
\text { college/university after form } 12 \text { or } 13 \text { (Fachabitur/Abitur) }\end{array}$ & 16 & 20 & 20 \\
\hline 5. University degree (Hochschulabschlu $\beta$ ) & 1 & 1 & 0 \\
\hline
\end{tabular}






Figure 3. Mean amplitudes ( \pm standard deviation) of tangential dipoles of the N1/ P2 component of auditory evoked potentials in nAm. Level of significance: ${ }^{*}: p<$ $.05,{ }^{* *}: p<.01,{ }^{* * *}: p<.001$ (paired twotailed $t$-test, Holm's procedure).
Paired two-tailed $t$-tests revealed no significant dependency of the tangential dipole activities from the stimulus intensity in the two control groups. In contrast, the ecstasy user group exhibited increasing amplitudes of the tangential dipole activity with ascending stimulus intensities (two-tailed paired $t$-tests and Holm's procedure: $60 / 70 \mathrm{~dB}: p=.019, \mathrm{df}=24, \mathrm{n}=25$; $70 / 80 \mathrm{~dB}: p=.000, \mathrm{df}=24, \mathrm{n}=25 ; 80 / 90 \mathrm{~dB}: p=.002$, $\mathrm{df}=22, \mathrm{n}=23$; missing data because of artifacts and technical reasons).

There was no significant correlation between the patterns of ecstasy and cannabis use and the dependency of the tangential dipoles on stimulus intensity in the group of ecstasy users. Although ecstasy users had significantly or at least marginally higher scores for experience seeking (subscale of the Sensation Seeking Scale) and for nonplanning impulsivity (subscale of the Barratt Impulsiveness Scale) than the control groups (table 3: descriptive statistics, ANOVA and Scheffé tests), there was no significant correlation between those psychometric scores and the dependency of the tangential dipoles on stimulus intensity.

\section{DISCUSSION}

Auditory evoked potentials with stimuli of increasing intensity were recorded in a group of 28 abstinent recreational ecstasy users with concomitant use of cannabis only and in two equally sized matched groups of cannabis users and nonusers. Dipole source analysis was performed to separate the tangential dipole of the N1/ P2 component, which mostly represents the highly serotonergically innervated primary sensory cortex, from the radial dipole, which represents the less densely serotonergically innervated secondary sensory cortex (Hegerl and Juckel 1993; Hegerl et al. 1994). The ecstasy user group exhibited a clear-cut increase of the ampli-

Table 3. Scores on Two Psychometric Scales (Group Means \pm Standard Deviation, $(n=28$ in Each Group) and Results of ANOVA (p) and Post Hoc Group Comparisons. Significant Group Differences Are Indicated by Bold Characters

\begin{tabular}{|c|c|c|c|c|c|c|c|}
\hline & \multicolumn{3}{|c|}{ Scores } & \multirow{2}{*}{$\begin{array}{c}\text { ANOVA } \\
\text { (p) }\end{array}$} & \multicolumn{3}{|c|}{ Scheffé p } \\
\hline & Esctasy Users & Cannabis Users & Nonusers & & $\mathrm{E} / \mathrm{N}$ & $\mathrm{E} / \mathrm{C}$ & $\mathrm{C} / \mathrm{N}$ \\
\hline \multicolumn{8}{|l|}{ Barratt Impulsiveness Scale BIS } \\
\hline Global score & $78.89 \pm 14.20$ & $76.25 \pm 9.31$ & $73.36 \pm 7.94$ & n.s. & & & \\
\hline Motor & $24.04 \pm 3.77$ & $22.64 \pm 3.32$ & $22.54 \pm 3.04$ & n.s. & & & \\
\hline Cognitive & $27.36 \pm 3.93$ & $27.68 \pm 4.18$ & $25.79 \pm 2.79$ & n.s. & & & \\
\hline Nonplanning & $28.93 \pm 4.83$ & $25.93 \pm 4.87$ & $25.04 \pm 4.52$ & .008 & * & $* *$ & n.s. \\
\hline \multicolumn{8}{|l|}{ Sensation Seeking Scale SSS-V } \\
\hline Global score & $25.18 \pm 4.27$ & $25.29 \pm 4.28$ & $22.46 \pm 4.57$ & .028 & $* *$ & n.s. & $* *$ \\
\hline Experience seeking & $8.50 \pm 1.0$ & $7.21 \pm 1.6$ & $7.64 \pm 1.64$ & .004 & $* *$ & * & n.s. \\
\hline Disinhibition & $6.07 \pm 2.11$ & $6.25 \pm 2.29$ & $5.75 \pm 1.99$ & n.s. & & & \\
\hline Boredom susceptibility & $3.93 \pm 1.65$ & $4.11 \pm 1.59$ & $3.64 \pm 1.16$ & n.s. & & & \\
\hline Thrill and adventure seeking & $6.68 \pm 2.61$ & $7.71 \pm 2.72$ & $5.43 \pm 2.17$ & .004 & n.s. & n.s. & * \\
\hline
\end{tabular}

n.s. $=$ not significant, ${ }^{*}=p<.05, * *=p<.1$

$\mathrm{E} / \mathrm{N}=$ Ecstasy users / Non-users; $\mathrm{E} / \mathrm{C}=$ Ecstasy users / Cannabis users; $\mathrm{C} / \mathrm{N}=$ Cannabis users / Non-users. 
tude of the tangential dipole of the N1/P2 component with the higher stimulus intensities; whereas, both matched control groups failed to exhibit this feature. These data are in line with the hypothesis that abstinent ecstasy users present with diminished serotonergic activity in the central nervous system.

The high intensity dependence of the N1/P2 tangential dipole source activity is likely to represent a consequence of the use of ecstasy. The ecstasy users reported an average time period of more than 3 weeks from the last intake of ecstasy to the study day. Therefore, purely pharmacological effects and functional "after effects" of the drug are unlikely to have determined the data. Differences across the three groups in the degree of attention paid to the stimuli are also unlikely to have influenced the data substantially. First, all subjects were instructed to relax and give little attention to the stimuli, and there were no other attentional tasks involved in the experimental procedure. Second, a number of recent studies on the cognitive performance of ecstasy users have failed to reveal differences in basic cognitive skills between users and controls (Krystal et al. 1992; Parrott et al. 1998; Parrott and Lasky 1998; Semple et al. 1999). In conclusion, the high intensity dependence of the N1/P2 tangential dipole source activity probably represents a long-term alteration in information processing attributable to neurotoxic effects of ecstasy. It is noteworthy that our sample of ecstasy users did not include very heavy or polydrug users. Our data raise concerns that ecstasy use, even in typical recreational doses, may lead to long-term changes in brain function (and possibly structure) of otherwise healthy young individuals. Although we cannot rule out the possibility that subjects concealed concomitant regular use of other legal and illegal drugs and/or heavier ecstasy use, we do not think that this is the case, because subjects were unaware of our inclusion and exclusion criteria when first interviewed, and there was no motivation for them to falsify their data once they agreed to participate in the study. In addition, our clinical impression of the ecstasy users did not fit the typical characteristics of heavy polydrug users.

At first glance, the lack of a correlation between the intensity dependence of the auditory dipole source activity and the extent of ecstasy use seems intriguing. One possible explanation for that may be that the alteration of information processing emerges relatively early after the onset of regular ecstasy use. In addition, individual sensitivity to the drug may play a more important role for the development of a high intensity dependence of the auditory dipole source activity than the cumulative dose administered. However, we cannot exclude the possibility that the high intensity dependence of the auditory evoked N1/P2 activity in ecstasy users was not caused by the use of ecstasy. Alternatively, it might represent a pre-existing characteristic feature of information processing in ecstasy users. Evidence from both older and more recent work suggests a relationship between high intensity dependence of sensory evoked potentials and such distinct personality traits as high sensation seeking, novelty seeking, extraversion, impulsivity, and psychopathy (Barrat et al. 1987; Carrillo-de-la-Pena 1992; Hegerl and Juckel 1993; Hegerl et al. 1989, 1994, 1995a, 1995b; Juckel et al. 1995; Lukas 1987; Raine 1989; Raine and Venables 1990; Stenberg et al. 1988; Zuckerman 1990; Zuckerman et al. 1988). Within the augmenting/reducing concept first proposed by Buchsbaum and Silverman (1968) a high intensity dependence (augmenting) of sensory evoked activity is viewed as reflecting a central mechanism regulating neuronal sensitivity and providing the organism with an optimal level of sensory stimulation. Moreover, a relationship between high intensity dependence of sensory evoked potentials and the development of drug or alcohol abuse is also discussed in the older literature (Zuckerman 1972). Hence, the high intensity dependence of the auditory evoked dipole source N1/P2 activity in our sample of ecstasy users might represent a predisposing factor for the development of drug use in general, rather than a consequence of the use of ecstasy. However, we found no significant intensity dependence of the evoked potentials in our group of cannabis users. Moreover, the correlation analyses of the electrophysiological and psychometric data did not support a link between high intensity dependence and distinct personality characteristics in our sample of ecstasy users. Last but not least, the intensity dependence of the tangential dipole source N1/P2 activity in our sample of ecstasy users was more pronounced than that reported by Juckel and co-workers (1995) in their sample of healthy people with high novelty seeking. Taken together, these findings oppose the conception of the high intensity dependence being a pre-existing feature associated with personality traits in our ecstasy users, and they support the view of the high intensity dependence being caused by the use of ecstasy.

Interestingly, we were unable to demonstrate an intensity dependence of the tangential dipole source N1/ P2 activity in our two control samples. This negative finding seems to contradict the data from several studies demonstrating an increase of the N1/P2 amplitude with increasing sound intensity (Naatanen and Picton 1987) and particularly the data of Hegerl and Juckel (1993) and Juckel and co-workers (1995), who used the same procedures for dipole source analysis of the auditory evoked N1/P2 activity as we did. However, a methodological detail may be responsible for these seemingly conflicting results: because of technical limitations of the used Pathfinder Mega ${ }^{\mathrm{R}}$, we presented the acoustic stimuli in blocks of ascending intensity; whereas, other groups preferred to use a randomized presentation of stimuli of different intensities to minimize habituation (Hegerl and Juckel 
1993; Juckel et al. 1995). According to a recent study by Carrillo-de-la Pena (1992), randomized stimulus presentations produce higher amplitudes in the high intensity levels than ascending or descending block presentations. This effect may be attributable to a lower degree of habituation with randomized presentation of stimuli. In that case, a randomized stimulus presentation might have caused a detectable intensity dependence of the N1/P2 dipole source activity in our two control groups, thus matching the data of Hegerl and Juckel (1993) and Juckel and co-workers (1995). However, it would have also caused an even stronger intensity dependence in the group of ecstasy users than the one demonstrated with our methods.

In summary, and despite some incertitude, our data suggest that ecstasy use over a period of months or few years may cause long-term alterations in information processing, even when it is taken in typical recreational doses and not necessarily in very high doses. This alteration is likely to be related to the well-recognized neurotoxic potential of ecstasy, which is restricted to the serotonergic system. A most important question refers to the reversibility or permanence of this effect after longer periods of abstinence. This question cannot be answered in cross-sectional studies and must be addressed in future longitudinal investigations. Given the popularity of ecstasy among young people, the present data underline the need for further research in this field.

\section{ACKNOWLEDGMENTS}

This work was supported by a grant to the last author (E.G.M.) from the Deutsche Forschungsgemeinschaft (DFG Go $717 / 2-1)$. Some results form part of the doctoral theses of the first author (F.T.) and the fifth co-author (S.P.) at the Medical Faculty of the University of Technology Aachen (D 82). We thank Professor Dr. M. J. Bogusz, Institute of Forensic Medicine at the RWTH, for the performance of the drug screens.

\section{REFERENCES}

Azmitia EC, Gannon PJ (1986): The primate serotonergic system: A review of human and animal studies and a report of macaca fascicularis. Adv Neurol 43:407-468

Barratt ES (1985): Impulsiveness subtraits: Arousal and information processing. In Spence JT, Izard CE (eds), Motivation, Emotion, and Personality. North Holland, Elsevier, pp 137-146

Barrat ES, Pritchard WS, Faulk DM, Brandt ME (1987): The relationship between impulsiveness subtraits, trait anxiety, and visual N100 augmenting/reducing: A topographic analysis. Person Individ Diff 8:43-51

Battaglia G, Yeh SY, O'Hearn E, Molliver ME, Kuhar MJ, De Souza EB (1987): 3,4-methylenedioxymethamphetamine and 3,4-methylenedioxyamphetamine destroy serotonin terminals in rat brain: Quantification of neurodegeneration by measurement of $\left[{ }^{3} \mathrm{H}\right]$ paroxetine-labelled serotonin uptake sites. J Pharmacol Exp Ther 242:911-916

Battaglia G, Yeh SY, De Souza EB (1988): MDMA-induced neurotoxicity: Parameters of degeneration and recovery of brain serotonin neurons. Pharmacol Biochem Behav 29:269-274

Benazzi F, Mazzoli M (1991): Psychiatric illness associated with "Ecstasy." Lancet 338:1520

Bolla KI, McCann DU, Ricaurte GA (1998): Memory impairment in abstinent MDMA ("Ecstasy") users. Neurology 51:1532-1537

Bruneau N, Barthelemy C, Roux S, Jouve J, Lelord G (1989): Auditory evoked potential modifications according to clinical and biochemical responsiviness to fenfluramine treatment in children with autistic behavior. Neuropsychobiology 21:48-52

Buchsbaum MS, Silverman J (1968): Stimulus intensity control and cortical evoked response. Psychosom Med 30:12-22

Campbell MJ, Lewis DA, Foote SL, Morrison JH (1987): Distribution of choline acetyltransferase-, serotonin-, dopamine-b-hydroxylase-, tyrosine hydroxylase-immunoreactive fibers in monkey primary auditory cortex. J Comp Neurol 261:209-220

Carrillo-de-la-Pena MT (1992): ERP augmenting/reducing and sensation seeking: A critical review. Int J Psychophysiol 12:211-220

Carrillo-de-la-Pena MT (1998): Effect of stimulus intensity and order of stimulus presentation on auditory evoked potentials (AEPs). An analysis of the consistency of augmenting/ reducing (A/R) Phenomenon. Int J Psychophysiol Nr 12:214

Fischer C, Hatzidimitriou G, Wlos J, Katz J, Ricaurte G (1995): Reorganization of ascending 5-HAT axon projections in animals previously exposed to the recreational drug 3,4-methylenedioxymethamphetamine (MDMA, Ecstasy). J Neuroscience 15:5476-5485

Gerra G, Zaimovic A, Giucastro G, Maestri D, Monica C, Sartori R, Caccavari R, Delsignore R (1998): Serotonergic function after 3,4-methylenedioxymethamphetamine (Ecstasy) in humans. Intern Clin Psychopharmacol 13:1-9

Gouzoulis-Mayfrank E, Hermle L, Kovar K- A, Sass H (1996): The entactogens: "Ecstasy" (MDMA), "Eve" (MDE) and other ring-substituted methamphetamine derivatives. A novel pharmacological class among the illicit designer drugs? Nervenarzt 67:369-380

Green AR, Cross AJ, Goodwin GM (1995): Review of the pharmacology and clinical pharmacology of 3,4-methylenedioxymethamphetamine (MDMA or "Ecstasy"). Psychopharmacology 119:246-260

Hegerl U, Juckel G (1993): Intensity dependence of auditory evoked potentials as an indicator of central serotonergic neurotransmission: A new hypothesis. Biol Psychiat 33:173-187

Hegerl U, Ulrich G, Müller-Oerlinghausen B (1987): Auditory evoked potentials and response to lithium prophylaxis. Pharmacopsychiatry 20:213-216

Hegerl U, Prochno I, Ulrich G, Müller-Oerlinghausen B (1989): Sensation seeking and auditory evoked potentials. Biol Psychiat 25:179-190 
Hegerl U, Juckel G, Rao ML, Müller-Oerlinghausen B (1991): Blood serotonin and auditory evoked potentials under fluvoxamine challenge and phototherapy. In Cassano GB, Akiskal HS (eds), Serotonin-Related Psychiatric Syndromes: Clinical and Therapeutic Links. London, Royal Society of Medicine, pp 163-170

Hegerl U, Wulff H, Müller-Oerlinghausen B (1992): Intensity dependence of auditory evoked potentials and clinical response to prophylactic lithium medication: A replication study. Psychiat Res 44:181-191

Hegerl U, Gallinat J, Mrowinski D (1994): Intensity dependence of auditory evoked dipole source activity. Int J Psychophysiol 17:1-13

Hegerl U, Gallinat J, Mrowinski D (1995a): Sensory cortical processing and the biological basis of personality. Biol Psychiat 37:467-472

Hegerl U, Lipperheide K, Juckel G, Schmidt LG, Rommelspacher H (1995b): Antisocial tendencies and cortical sensory evoked responses in alcoholism. Alcohol Clin Exp Res 19:31-36

Hegerl U, Juckel G, Müller HJ (1996): Event-related cortical potentials as indicators of neurochemical dysfunction in psychiatric patients. Nervenarzt 67:360-368

Juckel G, Schmidt LG, Rommelspacher H, Hegerl U (1994): The tridimensional personality questionnaire and the intensity dependence of auditory evoked dipole source activity. Biol Psychiat 37:311-317

Krystal JH, Price LH, Opsahl C, Ricaurte GA, Heninger GR (1992): Chronic 3,4-methylenedioxymethamphetamine (MDMA) use: Effects on mood and neuropsychological function? Am J Drug Alcohol Abuse 18:331-341

Lewis DA, Campbell MJ, Foote SL, Goldstein M, Morrison JH (1987): The distribution of tyrosine hydroxylaseimmunoreactive fibers in primate neocortex is widespread but regionally specific. J Neurosci 7:279-290

Lukas JH (1987): Human augmenting-reducing and sensation seeking. Psychophysiol 19:333-334

McCann DU, Ricaurte GA (1991): Lasting neuropsychiatric sequelae of (+)-methylenedioxymethamphetamine ("Ecstasy") in recreational users. J Clin Psychopharmacol 11:302-305

McCann DU, Szabo Z, Scheffel U, Dannals RF, Ricaurte GA (1998): Positron emission tomographic evidence of toxic effect of MDMA ("Ecstasy") on brain serotonin neurons in human beings. Lancet 352: 1433-1437

McGuire PK, Cope H, Fahy TA (1994): Diversity of psychopathology associated with use of 3,4-methylenedioxymethamphetamine ("Ecstasy"). Br J Psychiat 165:391-395

Molliver ME, Berger UV, Mamounas LA, Molliver DC, O'Hearn EG, Wilson MA (1990): Neurotoxicity of MDMA and related compounds. Ann NY Acad Sci 600:640-646

Morgan MJ (1998): Recreational use of "ecstasy" (MDMA) is associated with elevated impulsivity. Neuropsychopharmacology 19: 252-264

Morgan MJ (1999): Memory deficits associated with recreational use of "ecstasy" (MDMA). Psychopharmacology 141:30-36

Morrison JH, Foote SL (1986): Noradrenergic and serotonergic innervation of cortical, thalamic, and tectal visual structures in old and new world monkeys. J Comp Neurol 243:117-138

Naatanen R, Picton T (1987): The N1 wave of the human electric and magnetic response to sound: A review and an analysis of the component structure. Psychophysiology 24:375-425

O'Hearn EG, Battaglia G, De Souza EB, Kuhar MJ, Molliver ME (1988): Methylenedioxyamphetamine (MDA) and methylenedioxymethamphetamine (MDMA) cause selective ablation of serotonergic axon terminals in forebrain: Immunocytochemical evidence for neurotoxicity. J Neurosci 8:2788-2803

Pallanti S, Mazzi D (1992): MDMA (Ecstasy) precipitation of panic disorder. Biol Psychiat 32:91-95

Parrott AC, Lasky J (1998): Ecstasy (MDMA) effects upon mood and cognition: Before, during, and after a Saturday night dance. Psychopharmacology 139:261-268

Parrott AC, Lees A, Garnham NJ, Jones M, Wesnes K (1998): Cognitive performance in recreational users of MDMA ("ecstasy"): Evidence for memory deficits. J Psychopharmacol 12:79-83

Price LH, Ricaurte GA, Krystal JH, Heninger GR (1989): Neuroendocrine and mood responses to intravenous L-tryptophane in MDMA users. Arch Gen Psychiat 46:20-22

Raine A (1989): Evoked potentials and psychopathy. Int J Psychophysiol 8:1-16

Raine A, Venables PH (1990): Evoked potential augmentingreducing in psychopaths and criminals with impaired smooth-pursuit eye movements. Psychiat Res 31:85-98

Ricaurte GA, Bryan G, Strauss L, Seiden L, Schuster C (1985): Hallucinogenic amphetamine selectively destroys brain serotonin nerve terminals. Science 229:986-988

Ricaurte GA, Forno LS, Wilson MA, DeLanney LE, Irwin I, Molliver ME, Langston JW (1988): MDMA selectively damages central serotonergic neurons in the primate. JAMA 260:51-55

Ricaurte GA, Martello AL, Katz JL, Martello MB (1992): Lasting effects of MDMA on central serotonergic neurons in nonhuman primates: Neurochemical observations. J Pharmacol Exp Ther 261:616-622

Scherg M (1991): Akustisch evozierte Potentiale-Grundlagen, Entstehungsmechanismen, Quellenmodell. Stuttgart: Kohlhammer

Scherg M, Vajsar J, Picton TW (1989): Source analysis of the late human auditory evoked potentials. J Cogn Neurosci 4:336-355

Schmidt CJ (1987): Acute administration of methylenedioxymethamphetamine: Comparison with the neurochemical effects of its N-desmethyl and N-ethyl analogs. Eur J Pharmacol 136:81-88

Semple DM, Ebmeier KP, Glabus MF, O'Carroll RE, Johnstone EC (1999): Reduced in vivo binding to the serotonin transporter in the cerebral cortex of MDMA ("ecstasy") users. Br J Psychiat 175: 63-69

Stenberg G, Rosen I, Risberg J (1988): Personality and augmenting/reducing in visual and auditory potentials. Person Indiv Diff 9:571-579

Takeuchi Y, Sano Y (1983): Immunohistochemical demonstration of serotonin nerve fibers in the neocortex of the monkey (Macaca fuscata). Anat Embryol 166:155-168 
Von Knorring L (1982): Effect of imipramine and zimelidine on the augmenting-reducing response of visual-evoked potentials in healthy volunteers. Adv Biol Psychiat 9:81-86

Von Knorring L, Perris C (1981): Biochemistry of augmenting/reducing response in visual evoked potentials. Neurophysiol 7:1-8

Von Knorring L, Johansson F, Almay B (1980): Augmenting/ reducing response in visual evoked potentials with chronic pain syndromes. Adv Biol Psychiat 4:55-62

Wilson MA, Ricaurte GA, Molliver ME (1989): Distinct morphologic classes of serotonergic axons in primates exhibit differential vulnerability to the psychotropic drug 3,4-Methylenedioxymethamphetamine. Neuroscience 28:121-137

Zuckerman M (1972): Drug usage as one manifestation of a "sensation-seeking" trait. In Keup W (ed), Drug Abuse:
Current Concepts and Research. Springfield, IL: Charles C. Thomas, pp 154-163

Zuckerman M (1990): The psychophysiology of sensation seeking. J Pers 58:313-345

Zuckerman M, Murtaugh T, Siegel J (1974): Sensation seeking and cortical augmenting/ reducing. Psychophysiology 11:535-542

Zuckerman M, Eysenck SPG, Eysenck HJ (1978): Sensation seeking in England and America. J Consult Clin Psychol $46: 477-482$

Zuckerman M, Simons R, Como PG (1988): Sensation seeking and stimulus intensity as modulators of cortical, cardiovascular, and electrodermal response: A crossmodality study. Person Indiv Diff 9:361-372 